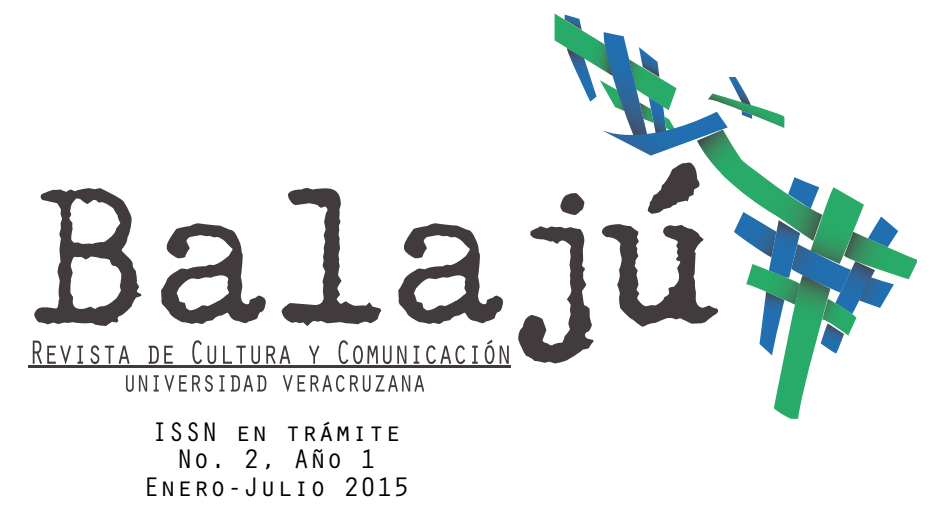

\title{
Cultura política del diario La Nueva Provincia en la gestación del peronismo
}

\author{
César Alejandro Violi Cattaneo \\ Universidad Nacional del Sur (UNS), Bahía Blanca, Argentina. \\ alejandrovioli@gmail.com
}

\section{RESUMEN}

El presente trabajo pretende reconstruir la cultura política de La Nueva Provincia en el período que va desde el golpe de Estado del 4 de Junio de 1943 al triunfo del peronismo en febrero de 1946. En cuanto al objetivo específico, la intención es observar qué postura adoptó el diario ante el período y acontecimientos presentados. Además, se hará hincapié en la forma en que fue visto el crecimiento de la figura de Juan Domingo Perón.

Abordaremos el estudio del período mencionado (1943-1946), empleando a los efectos de su análisis el concepto de Cultura Política, entendiendo al mismo como un conjunto de representaciones portadoras de actitudes, creencias, ideales, valores y conocimientos que constituyen la identidad de las grandes familias políticas. Consideramos que, al mismo tiempo que estructura las conductas políticas de los individuos, es un fenómeno colectivo que funda la identidad del grupo.

La presente propuesta pretende contribuir al análisis de la cultura política de la Nueva Provincia durante un período prácticamente no estudiado intentando tomarlo como una fase con entidad propia y no como mero tránsito hacia el gobierno de Juan Domingo Perón.

\begin{abstract}
This paper aims to reconstruct the political culture of the new province in the period from the coup of June 4, 1943 to the triumph of Peronism in February 1946. As for the specific purpose, the intent is to observe what position adopted daily events before the period presented. In addition, emphasis will be placed on how growth was seen in the figure of Juan Domingo Peron.
\end{abstract}

We will approach the study of the period mentioned (1943-1946), using for the purpose of analysis the concept of Political Culture, understanding it as a set of carriers representations of attitudes, beliefs, ideals, values and knowledge that constitute the identity of the large political families. We believe that, while the political structure behavior of individuals is a collective phenomenon that establishes the identity of the group.

This proposal aims to contribute to the analysis of the political culture of the new province for a period not studied practically trying to take it as a phase in its own right and not as a mere transition to the government of Juan Domingo Peron.

\section{PALABRAS CLAVES}

Peronismo, Cultura Política, Historia Argentina, Prensa, La Nueva Provincia

\section{KEYWORDS}

Peronism, Political Culture, Argentine History, Press, La Nueva Provincia 


\title{
Cultura política del diario La Nueva Provincia en la gestación del peronismo
}

\author{
Cualquiera que haya tenido algún tipo de contacto con la Argentina \\ y con la producción de sus intelectuales habrá podido comprobar \\ que en este país pocas palabras permiten \\ referencias a una gama tan amplia de sentidos como la palabra peronismo.
}

FEDERICO NEIBURG, Los intelectuales y la invención del peronismo

\section{Introducción}

El periodo iniciado con el golpe de estado que en junio de 1943 puso fin al gobierno de Ramón S. Castillo y que culmina con el triunfo electoral de la coalición encabezada por Juan Domingo Perón, en febrero de 1946, constituye una etapa rica en hechos y transformaciones tanto en el orden político como en el orden social. La gestación y nacimiento de un nuevo actor político, el peronismo, conformaría una cultura política definida como expresión de un movimiento de masas ${ }^{1}$.

En este marco, la prensa nacional se vio inmersa en una serie de discusiones y divisiones delimitadas por las diferentes posturas adquiridas ante la gestación del "hecho peronista" 2 . La prensa nacionalista, por su parte, saludó con alborozo el nuevo régimen surgido con el golpe de junio de $1943^{3}$. Otros periódicos, como La Vanguardia, sufrieron clausuras por parte del régimen militar. Los análisis sobre el periodo prácticamente sólo se ocupan de los grandes órganos de prensa de circulación nacional, y son muy escasos los estudios y las menciones a la prensa del interior. En cuanto a los medios impresos de la provincia de Buenos Aires, no han sido objeto de estudio salvo para épocas anteriores a 1943 o posteriores a $1946^{4}$. En el plano local, observamos que el periodo 19431946 ha sido escasamente trabajado y, sin embargo, ha ocupado gran parte de las editoriales y comentarios de la prensa.

Las alternativas producidas en el escenario político fueron segui-

1 Utilizamos la noción de cultura política empleada por Serge Bernstein y Jean-Francois Sirinelli para quienes la misma constituye un conjunto coherente de diversos componentes reunidos en un todo homogéneo que permite caracterizar la identidad de un agente social dado, sea éste individual o colectivo, y que conduce a proveerlo de una determinada visión del mundo. En dicha visión confluyen básicamente una matriz filosófica, una lectura común y normativa del pasado histórico y una concepción institucional que se traduce en una concepción de la organización política del estado. Todos estos elementos conforman un universo significativo que se expresa a través de un lenguaje político específico, conformado por palabras claves (citado en Mabel Cernadas y Laura Llull, Del apoyo a la crítica: itinerario de las ideas de La Nueva Provincia en los orígenes del peronismo). 2 La expresión pertenece a Carlos Altamirano, Bajo el Signo de las masas (1943-1973), p. 19. Véase también Cristian Buchrucker, Nacionalismo y peronismo. La Argentina en la crisis ideológica mundial (1927-1955).

3 Cristian Buchrucker, op. cit., p. 281.

4 María Liliana Da Orden y Julio César Melon Pirro, Prensa y peronismo. Discursos, prácticas, empresas, 19431958, p. 16. 
das con interés por los medios de prensa tanto nacionales como locales, los que, desde distintos lugares de enunciación y con diferentes perfiles discursivos, reflexionaron sobre el proceso. En este sentido, el objetivo general del presente trabajo consiste en reconstruir, a partir del concepto de cultura política, la manera en que La Nueva Provincia $(L N P)^{5}$ analizó la dinámica de los acontecimientos que culminaron con el triunfo del peronismo en febrero de 1946.

En cuanto a los objetivos específicos, la intención es examinar las diferentes posturas que fue adoptando el diario frente al "hecho peronista”, prestando especial atención a la forma en que fue vista la injerencia en la vida política de la figura de Juan Domingo Perón.

En esta investigación se parte de la hipótesis de que $L N P$ se convirtió en un vector principal de difusión de las culturas políticas durante el siglo XX, ya que el mismo, como actor político, contribuyó a definir la identidad política de sus lectores, inspirando sentimientos, moldeando sus sensibilidades y difundiendo sus representaciones. Emprendemos el estudio de un diario como $L N P$ por el insuficiente desarrollo de las investigaciones sobre la complejidad del pensamiento político de periódicos publicados en distintas ciudades del Interior del país, en general, y de la Provincia de Buenos Aires, en particular. En este sentido, creemos que abordar el estudio de un diario bahiense desde la perspectiva de su cultura política podría llegar a construir un aporte original y valioso para la comprensión de la evolución de las ideas políticas en el periodo.

La importancia de abordar el análisis de $L N P$ radica en que el matutino se constituyó en uno de los principales agentes socializadores para los lectores que frecuentaban las páginas editoriales de sus publicaciones diarias. Dicho periódico, como difusor de una cultura política, influyó marcadamente en sus lectores, transmitiendo una cultura política democrática.

Abordaremos el estudio del periodo 1943-1946 empleando a los efectos de su análisis el concepto de cultura política. Se trata de un concepto complejo, definido por distintas ramas de las ciencias sociales como la antropología, la sociología, las ciencias políticas y la historia de la cultura, entre otras.

En virtud de las múltiples definiciones existentes, en este trabajo adoptamos aquella que entiende a la cultura política como un conjunto de representaciones portadoras de actitudes, creencias, ideales, valores y conocimientos que constituyen la identidad de las grandes familias políticas. Consideramos que, al mismo tiempo que estructura las conductas políticas de los individuos, es un fenómeno colectivo que funda la

5 Periódico fundado en 1898 en la ciudad de Bahía Blanca, Provincia de Buenos Aires, Argentina. 
identidad del grupo ${ }^{6}$. Como señala Mabel Cernadas 7 , podemos decir que grupos enteros, aunque pertenezcan a distintas generaciones, comparten postulados, interpretaciones, propuestas, y utilizan los mismos discursos, los mismos signos y participan de los mismos rituales.

Las culturas políticas son fenómenos colectivos que, por tanto, conciernen a un mismo tiempo a grupos enteros que participan de los postulados, los puntos de vista, las interpretaciones, las propuestas, que apelan a los mismos discursos, comparten idénticos signos y participan de los mismos rituales.

Es importante mencionar que las raíces filosóficas y las referencias históricas juegan también un rol trascendente como fundamentos de las culturas políticas, porque no existe cultura política coherente que no comprenda, precisamente, una representación de la sociedad ideal y los medios de llegar a tenerla. En otros términos, raíces filosóficas, referencias históricas y régimen político inducen una imagen de la sociedad y del sitio que el hombre posee en ella. De esta forma, al ofrecer una grilla de lectura de lo social, esclarecida por el conjunto de datos que concurren a su definición, las culturas políticas aportan una clave de inteligibilidad aparente de los hechos cotidianos y de las soluciones supuestas a las dificultades de los hombres.

Por tanto, el planteo que origina nuestro interés por el estudio de las culturas políticas radica en la relación estrecha que une estas últimas a los actos políticos de los individuos. Éstos, a lo largo de sus vidas, van internalizando una determinada grilla de lectura de la realidad, una particular visión del mundo y de lo político. Este fenómeno de interiorización los lleva a militar por una causa, a comprometerse con una fuerza política, a votar por un candidato y no por otro. En este estadio, la cultura política está interiorizada.

Fundamentalmente a partir del siglo XX, los medios de comunicación -la prensa escrita y, con posterioridad, la radio y la televisión- se convirtieron en un vector principal de difusión de las culturas políticas ${ }^{8}$. Por otro lado, los periódicos contribuyeron a definir la identidad política de sus lectores, inspirando sentimientos y contribuyendo a moldear sensibilidades.

Asimismo, también tendremos en cuenta el planteo de Borrat, quien define al diario como un "actor político colectivo" capaz de afectar

6 Laura Llull, Prensa y Política en Bahía Blanca. La Nueva Provincia en las presidencias radicales, 1916-1930, p. 12.

7 Mabel Cernadas, "La cultura política: una herramienta compleja y sugerente de análisis de la realidad”, en Mabel Cernadas y Roberto Bustos Cara (eds.), La cultura en cuestión. Estudios interdisciplinarios del Sudoeste Bonaerense, pp 13-22. La autora toma el concepto de "cultura política" de Serge Bernstein y Jean-Francois Sirinelli como enunciamos anteriormente.

8 Laura Llull, Prensa y política en Bahía Blanca..., op. cit., p. 13. 
al proceso de toma de decisiones en dicho sistema. Según este autor, el ámbito de actuación del periódico no es el de la conquista del poder institucional o la permanencia en él sino el de la influencia que intenta ejercer sobre los otros actores que participan en éste ámbito y sobre la opinión pública en general ${ }^{9}$. De manera explícita o implícita, la línea política de un diario recorre y modela el temario de lo publicado, decidiendo inclusiones, exclusiones y jerarquizaciones tanto de las noticias como de los comentarios políticos.

Siguiendo las propuestas metodológicas de Borrat, estas sugerencias incluyen un análisis y una mención de la importancia que tienen los comentarios en la conformación de un periódico, otorgando a los acontecimientos un rango más elevado que el de aquellos temas que solamente son narrados. Pasar del relato al comentario es entrar en el campo de la opinión, que se articula con la interpretación explícita: es interpretación explícita con evaluación. Es el autor del texto el que hace la evaluación, el que comunica públicamente su toma de posición decidida en función de valores, normas e intereses. Los comentarios evalúan y toman posición acerca de los temas de la actualidad periodística, dando por supuesta, repitiendo o ampliando la información proporcionada por los correspondientes relatos informativos, pudiendo profundizar o modificar la interpretación que ellos proporcionaban, aplicando una escala de valores, analizando lo que ha ocurrido, lo que está ocurriendo o lo que está por ocurrir.

Por ello, entendemos que los medios de comunicación se convirtieron en vectores de difusión de culturas políticas durante el siglo XX, ya que los mismos favorecieron la definición de la identidad política de sus lectores.

\section{Desarrollo}

En los años que abarca este estudio, la prensa escrita tenía un rol protagónico que todavía no le había sido disputado por la televisión, lo que acentuaba su posición privilegiada en cuanto a la capacidad de crear y/o reproducir conceptos, significados, esquemas cognitivos, modelos interpretativos a través de los cuales los individuos le dan sentido a su propia experiencia ${ }^{10}$.

De esta manera, el periódico, en su carácter de medio de comuni-

9 Héctor Borrat, El periódico, actor político.

10 Irene Vasilachis de Gialdino, La construcción de representaciones sociales. Discurso político y prensa escrita. Un análisis sociológico, jurídico y lingüístico, p. 265, citado en Laura Llull, "El periódico como vector de internalización de una cultura política: La Nueva Provincia (1916-1922)”, Roberto Bustos Cara y Mabel N. Cernadas de Bulnes (eds.), Estudios Regionales Interdisciplinarios II, p. 245. 
cación masiva, juega el rol de un actor más del campo político, puesto en interacción con los otros, circunstancia ésta que implica que puede afectar al proceso de toma de decisiones en dicho campo, aunque su área de acción no sea aquella relativa a la conquista del poder institucional, sino la de la influencia. Los escenarios desde los que intenta ejercer esta influencia comprenden todos los espacios disponibles de la superficie redaccional.

\section{La Nueva Provincia}

El $1^{\circ}$ de agosto de 1898 se publicó en Bahía Blanca el primer ejemplar del matutino LNP. Su fundador y director, Enrique Julio, emprendió esta empresa para defender, desde sus páginas, la creación de un estado federal que abarcara los partidos del sur de la provincia de Buenos Aires y las gobernaciones que se extendían a largo de los ríos Negro y Colorado, y que tuviese como capital a la ciudad de Bahía Blanca.

En 1900, LNP ya se había convertido en uno de los establecimientos tipográficos más importantes de la provincia de Buenos Aires, y en las primeras décadas del siglo XX el matutino estaba en camino de convertirse en el diario que marcaría el horizonte periodístico de la prensa bahiense ${ }^{11}$.

A diferencia de sus colegas locales, que operaban con rotoplanas, $L N P$ disponía, desde 1910 , de una rotativa que le permitía un volumen y una calidad de edición superior, una singularidad técnica que se complementaba con una compleja estructura comercial, que posibilitaba que fuese "un diario de gran formato con ediciones de más de veinte páginas y tanta holgura económica que le permite hacer números extraordinarios" ${ }^{12}$. Esta solvencia se reflejaba también en la sede del diario, construida en 1929 en un punto destacado del área céntrica, próximo a la catedral y frente a la plaza central y al palacio municipal.

Su política empresarial incorporó modernas técnicas de impresión, dotó de nuevas secciones al diario y procuró ampliar el radio de cobertura hacia otras regiones en su intento de hegemonizar el sistema periodístico. Así, en 1926 se presentaba como el diario de mayor circulación en la provincia de Buenos Aires y en todo el sur del país. De esta forma, buscó atender a la realidad incontestable de la expansión de la demanda informativa por parte de un número considerable de nuevos lectores pertenecientes a todas las franjas sociales de un territorio que se iba poblando paulatinamente. En efecto, la extensión de la enseñanza pública y las consecuentes campañas de alfabetización realizadas en la ciudad y

11 Mabel Cernadas y Laura Llull, op. cit., p. 4.

12 Carlos Galván Moreno, El periodismo argentino, p. 299. 
su zona de influencia motivaron la ampliación del número de lectores de periódicos. De esta forma, se buscó desde el diario atender a esta expansión de la demanda informativa.

El fundador de $L N P$ justificaba el carácter comercial de la prensa moderna argumentando que, por sus características, la misma exigía un importante aporte de capital. Tal carácter no implicaba que fuesen olvidadas las "actividades superiores propias de la prensa": expresar su opinión sobre los distintos temas que preocupaban a los lectores. El objetivo principal de Enrique Julio había sido armonizar en su diario las funciones esenciales para la existencia de un diario: difusión y circulación de las noticias con aquella que conceptuaba como la más importante: analizar todas las cuestiones de interés general y orientar la opinión pública ${ }^{13}$. El capital simbólico adquirido a lo largo de su trayectoria en tanto medio de comunicación hizo que sus reflexiones editoriales sobre temas políticos fueran seguramente leídas con atención por su público.

A lo largo del periodo que nos compete, el diario enunció, desde sus editoriales, la importancia de los partidos políticos en la democracia, su concepción sobre el rol de la prensa y sobre el rol que deben jugar las Fuerzas Armadas (FF.AA) en la nación.

Uno de los ejes principales de la cultura política de $L N P$, a partir del proceso democrático, fue la idea del progreso político-institucional. Progreso que, en su opinión, implicaba el triunfo de los "partidos orgánicos", a los que percibía como verdaderos paradigmas de la modernidad política, puesto que orientaban su acción sobre la base de un conjunto de ideas y con exclusión casi sistemática de "personalismos perturbadores".

Inmediatamente antes de producirse el golpe de junio de 1943, con términos inequívocos, el diario sostuvo que las prácticas de "negación democrática" representadas en el "caudillismo criollo" serían superadas cuando por vía legislativa se reglamentase la vida interna de los partidos y se regulase su funcionamiento para que constituyera una garantía de procedimientos correctos.

Una vez consumado el golpe del 4 de junio y luego de que el gobierno imperante disolviera los partidos políticos, el diario bahiense planteaba la necesidad de trabajar en pos de formar partidos políticos que actuaran "a manera de escuelas de civismo, formadores de una sólida cultura de los derechos y obligaciones que apareja la condición de ciudadano"14.

El periódico hizo constantes referencias, en distintas editoriales, a la necesidad de un estatuto para los partidos políticos, y junto con ello propugnaba la idea de no precipitar los hechos para construir sobre sólidos cimientos la base para la renovación democrática. Es por ello que, 13 Laura Llull, Prensa y Politica en Bahía Blanca..., op. cit., p. 49.

14 "La disolución de los partidos políticos", La Nueva Provincia, 4 de enero de 1944, p. 2. 
frente a la intervención militar (como veremos más adelante), en ocasiones manifestaba que aunque esto no era lo ideal para la política, sí era necesario como paso previo para la consolidación y renovación de los partidos políticos.

Su principal preocupación era la salida electoral, inquietud que se manifestaba tanto desde las editoriales como desde las noticias, ocupando grandes espacios en el interior del periódico:

¿Qué ganaría el país con precipitar los hechos, dejar inconclusa la actual obra
en sus postulados esenciales y promover el retorno al campo político de mu-
chas situaciones y factores personales implicados o culpables de mil y un pe-
cados de lesa democracia? No es cuestión de regresar nominalmente, o por
vía formal, al llamado estado de plenitud constitucional y caer, de hecho, en la
dolorosa ficción de gobiernos populares como los sufridos, con una pequeña
excepción, en los últimos trece años anteriores a $1943 .{ }^{15}$

Cuando finalmente, en mayo de 1945, se conoció el Estatuto de los partidos políticos, el matutino volvió a dedicarle una nota editorial al tema que siempre lo había preocupado. Entendía que, en su conjunto, el estatuto constituía un cuerpo excelente de normas, ya que tendía a "rehabilitar la ciudadanía transformando los centros políticos en escuela de democracia, quitando a las oligarquías caciquiles su nefasto predominio". Sin embargo, también encontraba en dicho documento algunas disposiciones que debían ser objeto de revisión.

Durante los primeros momentos del "gobierno de los coroneles", $L N P$ tuvo una visión positiva y de confianza hacia los gobernantes. Entendía y transmitía en sus editoriales que el propósito de aquéllos no era mantenerse vasto tiempo en el poder sino, por el contrario, reordenar la escena política para luego dar lugar al libre juego de la democracia. Es decir, aunque el periódico creía firmemente en la democracia como única y legítima forma de gobierno, entendía que, dada la situación del momento, las FF.AA eran las únicas que podían garantizar el orden necesario para regresar hacia dicho régimen político. Es así como, haciéndose eco de declaraciones oficiales sobre la pronta vuelta a la democracia, el diario plantea una mirada satisfactoria sobre dichas palabras.

Esta situación va a cambiar hacia mediados de 1945, cuando el periódico empieza a desconfiar de los intereses del gobierno y denuncia en sus editoriales el posible "continuismo" de la dictadura. Allí comienzan a aparecer opiniones donde argumentan que las FF.AA deben dedicarse a sus deberes y alejarse de la arena política para dar paso al restablecimiento de las instituciones democráticas una vez logrado el orden nece-

15 “Los partidos y el pleno retorno a la Constitución”, La Nueva Provincia, 14 de agosto de 1944, p. 2. También encontramos constantes editoriales dedicadas a dicha temática: "La preparación del estatuto político" (8 de diciembre de 1944, p. 2); "La convocatoria a elecciones generales" (7 de enero de 1945, p. 2). 
sario:

En las grandes democracias del mundo, donde el soldado está, a su vez, fuertemente impregnado de las instituciones jurídicas que las rigen, la organización militar se desenvuelve en su plano profesional sin interferir en las esferas civiles ni ser perturbada por influencias extrañas a su misión.

[...] Porque el país ama sinceramente a sus soldados es porque los desea ver plenamente reintegrados a los cuarteles para bien de la disciplina y el más amplio prestigio de la institución. ${ }^{16}$

\section{Tiempo después agregaba:}

El deber del soldado es, efectivamente, servir a la Nación por arriba de las luchas lícitamente conformadas a la ley. Si, a veces, las circunstancias lo obligan a salir del cuartel para restablecer el orden conculcado o salvar situaciones susceptibles de desembocar en el caos o en la anarquía, esa incursión en el campo del gobierno civil debe limitarse al cumplimiento estricto de las razones extremas que espolearon el ánimo patriótico. ${ }^{17}$

\section{El golpe de Estado de junio de 1943}

Exactamente un mes antes de producirse el movimiento revolucionario de junio de 1943, LNP dedicaba su página editorial a reflexionar sobre la elección presidencial a realizarse en septiembre de ese año. No podía dejar de manifestar su preocupación ante el hecho de que ninguno de los partidos políticos que participarían en los comicios había proclamado sus candidatos, ni se ocupaba de la ineludible tarea de educar a las masas mediante "una intensa y fecunda labor de ilustración pública". El matutino local alertaba sobre la necesidad de que las fuerzas políticas formulasen un programa que fuera la expresión genuina de la voluntad de sus afiliados y, en virtud del mismo, estructurasen sus campañas electorales ${ }^{18}$.

La "Revolución de los Coroneles" marcó el comienzo de un capítulo decisivo en la integración de la comunidad política nacional. Dicho capítulo se caracterizaría por la emergencia de un nuevo actor político-social y un nuevo estilo de liderazgo: las clases populares y la figura de Juan Domingo Perón.

El país estaba cansado, en verdad, de tanta ficción, tanto fraude y tanto peculado como los que se han venido consumando en los últimos tiempos. El pronunciamiento contra tal política era, pues, necesario. Si bien toda solución al margen de las normas legales es siempre dolorosa, porque no sólo interrumpe la continuidad jurídica de las normas institucionales sino también porque en algunas circunstancias puede engendrar elementos de desvirtuación, la situación argentina de los últimos tiempos no admitía otro arbitrio. Los caminos

16 "La política, el gobierno y las instituciones armadas", La Nueva Provincia, 4 de septiembre de 1945, p. 2. 17 "Un soldado no puede ser otra cosa que soldado", La Nueva Provincia, 18 de diciembre de 1945, p. 2.

18 "El estado de sitio y los comicios presidenciales", La Nueva Provincia, 4 de mayo de 1943, p. 2. 
Con esas palabras se refería el matutino local al golpe perpetrado el día anterior (4 de junio) en la capital del país. Encontraba tranquilizadoras las intenciones expresadas por los jefes militares en el manifiesto revolucionario, que hablaban de responder a la demanda de moralización de la vida pública y señalaban la necesidad de mantener y afianzar las instituciones democráticas.

Dicha mirada positiva estuvo presente en la mayoría de las editoriales del periódico durante el primer año del gobierno surgido del golpe de 1943. Su creencia en la democracia como única forma de gobierno posible y aceptable hizo que justificara la intervención militar en más de una ocasión. Es decir, que si bien reconocía que cualquier solución al margen de los principios que establecía la Constitución resultaba potencialmente peligrosa, sostenía categóricamente que la situación en los últimos tiempos no admitía otro arbitrio. Junto con ello, la cuestión de los partidos políticos comienza a aparecer como una preocupación y plantea que se está en una coyuntura ideal para comenzar a depurarlos de las "prácticas internas, a fin de que la democracia argentina sea algo más que un hermoso tema para las abstracciones literarias" 20.

El gobierno instaurado el 4 de junio siguió contando con el apoyo del diario incluso un año después, y en su editorial, en ocasión del primer aniversario de aquel movimiento, expresaba:

\footnotetext{
Tres elementos singulares caracterizan y preponderan en el programa revolucionario del 4 de junio: salvaguardia y fortalecimiento del interés social de la población; plan de recuperación, para la integral soberanía del país, de los valores económicos locales; adecentamiento de las prácticas administrativas, en todos sus campos, hasta la creación de un orden de dignidad para la función pública y representativa una vez vuelto el país a la normalidad política. Ese programa no puede ser más plausible. ${ }^{21}$
}

Perpetrado el golpe de 1943 y consolidado el gobierno militar surgido de aquél, los oficiales del Grupo de Oficiales Unidos (GOU) creían que era imperativo elevar el nivel de vida de los trabajadores a efectos de evitar conflictos sociales. Para ello fue creada la Secretaría de Trabajo y Previsión, siendo designado al frente del mismo el coronel Juan Domingo Perón. Ante el mencionado suceso, LNP dedicó una editorial manifestando su aprobación frente a dicha creación, ya que consideraba que era imperativo "contemplar, proteger y orientar las actividades y problemas cone-

19 "Una nueva esperanza argentina”, La Nueva Provincia, 5 de junio de 1943, nota de tapa.

20 “La Revolución y los partidos políticos", La Nueva Provincia, 22 de junio de 1943, p. 2.

21 “En el primer aniversario de la Revolución de Junio", La Nueva Provincia, 4 de junio de 1944, p. 2. 
xos con el capital y el trabajo desde el punto de vista del interés social”22.

Perón, más consciente que sus camaradas de armas del carácter complicado de la situación social del país, y advertido de que el régimen militar no podría mantenerse mucho tiempo apoyándose en la fuerza, desplegó su acción política alrededor de tres ejes: la justicia social, el control de la clase obrera y la despolitización de las organizaciones sindica$\operatorname{les}^{23}$. El matutino bahiense comenzó a observar la importancia que fue adquiriendo el coronel y se hizo eco de los distintos homenajes que se le brindaban en sus distintas visitas a las ciudades del interior del país. Por otra parte, en sus editoriales reflejaba la labor que el gobierno surgido en 1943 estaba desarrollando en el ámbito social:

\begin{abstract}
La principal preocupación gubernativa se halla concentrada en el campo social. El anhelo de mejorar la condición del trabajador, de proporcionarle condiciones de vida más dignas en el orden de las exigencias económico-sociales del hogar y prestigiar su condición de factor fundamental en la actividad material del país, sin mengua para otros intereses legítimos, se ha traducido en diversas medidas acogidas con simpatía y calor. ${ }^{24}$
\end{abstract}

Y dos días después enunciaba: "Para corresponder con mayor amplitud y eficacia a las exigencias de los problemas del capital y del trabajo, fue creada a fines del año pasado la Secretaría de Trabajo y Previsión, dotada de facultades y medios adecuados a sus funciones equivalentes a un verdadero ministerio." 25

En consonancia con el gobierno, el diario de la familia Julio consideraba que era imperativamente necesario elevar el estándar de vida del pueblo argentino, mejorando sus sueldos para de esta manera "aumentar su capacidad adquisitiva y sus posibilidades económicas para una vida mejor" ${ }^{26}$. De esta manera inscribía la creación de la Secretaría de Trabajo y Previsión en el marco de la obra transformadora realizada por la revolución de junio y singularizaba especialmente la labor de Juan Domingo Perón al frente de la misma.

En un tono similar fue leído el decreto de octubre de 1944 por el que se aprobaba el estatuto del peón de campo: "El propósito determinante del estatuto es digno de aplauso. Sus disposiciones alcanzan a una realidad económica y social que hasta ahora no ha merecido atención efectiva de parte de los anteriores gobiernos" ${ }^{27}$.

En definitiva, la entrada a escena del coronel Perón fue bien recibi-

22 “La creación de la Secretaría de Trabajo y Previsión”, La Nueva Provincia, 3 de diciembre de 1943, p. 2.

23 Mario Rapoport, Historia económica, política y social de la Argentina (1880- 2000), p. 285.

24 "En el primer aniversario de la Revolución de Junio", La Nueva Provincia, 4 de junio de 1944, p. 2.

25 La Nueva Provincia, 6 de junio de 1944, p. 2.

26 Ibid., 27 de noviembre de 1944, p. 2.

27 "El estatuto del peón", La Nueva Provincia, 15 de octubre de 1944, p. 2. 
da por el matutino bahiense ya que consideraba que su labor era fundamental a los fines transformadores de la revolución del 4 de junio y veía en él a un funcionario que representaba fielmente los intereses democráticos que el diario perseguía ${ }^{28}$. El crecimiento de la figura del coronel fue seguido con atención por el periódico y de esta forma cada vez ocupaba más espacio en sus ediciones para reproducir y comentar sus discursos y declaraciones ${ }^{29}$.

En marzo de 1944, ante la renuncia de Pedro Pablo Ramírez y la asunción del general Edelmiro Farrel, el coronel Perón fue designado ministro de Guerra, conservando su cargo al frente de la Secretaría de Trabajo y Previsión. Sumado a ello, a principios de julio del mismo año, Perón fue designado vicepresidente, sin renunciar a los cargos anteriormente mencionados. Parecía, de esta forma, haber alcanzado la cumbre del poder, contando con una gran influencia en el gobierno y con el apoyo de algunos de sus camaradas ubicados estratégicamente en diversos cargos gubernamentales..$^{30}$

Ante dicho nombramiento, LNP esbozó una breve biografía del nuevo ministro de Guerra y poco tiempo después comenzó a hacerse eco de variadas declaraciones del nuevo funcionario sobre la política seguida por parte de Argentina en el ámbito internacional. En ocasión de declaraciones norteamericanas referidas a un discurso dado por Perón sobre política internacional, $L N P$ tomó postura a favor del coronel:

\footnotetext{
Es evidente, por lo demás, que las manifestaciones del coronel Perón han sido objeto de una interpretación deficiente. El propio secretario de Estado lo ha dicho ayer. Sus juicios fueron examinados con referencia a una versión literaria un tanto distinta de las manifestaciones originales, con el agregado de que no se ha estudiado toda la pieza dentro de su conjunto armónico. ${ }^{31}$
}

En julio de 1944, el matutino volvió a publicar los datos biográficos de Perón ante la designación del mismo al frente de la Vicepresidencia de la Nación, y al igual que venía sucediendo, su declaraciones fueron objeto de distintos comentarios y de una gran cobertura por parte del diario.

Hacia principios de 1945, en tanto Perón se proyectaba políticamente en la búsqueda de un apoyo popular, los partidos políticos, las

28 "Es de mérito la labor realizada por los diversos organismos de la repartición, cuya jefatura ejerce el coronel Juan D. Perón", en "Primer año de existencia de la Secretaría de Trabajo y Previsión", La Nueva Provincia, 27 de noviembre de 1944, p. 2.

29 Entre otros titulares podemos encontrar: "El coronel don Juan Perón, secretario de Trabajo y Previsión Social, dirigirá hoy, por radiotelefonía, la palabra a los trabajadores", 1 de mayo de 1944, p. 3; "Hoy viajará a Córdoba el ministro Coronel Perón", 28 de mayo de 1944, p. 3; "Diversos agasajos fueron tributados en el día de ayer, en Córdoba, al coronel Perón", 30 de mayo de 1944, p. 3; "Los tranviarios agasajaron anoche al coronel Juan Domingo Perón", 21 de julio de 1944, p. 3.

30 Mario Rapoport, op. cit., p. 287.

31 "Equívocos lamentables en el campo americano", La Nueva Provincia, 4 de julio de 1944, p. 2. 
entidades empresariales, las organizaciones estudiantiles y la prensa nacional aunaban sus voces y estrechaban filas, intentando alejar a los militares del gobierno. Por su parte, $L N P$ planteaba que "el país, y todos los ciudadanos, desean efectivamente el retorno al juego libre de todas las instituciones, pero sin apremios ni, tampoco, dilaciones de tiempo" 32 .

Las medidas adoptadas por Perón en favor de los trabajadores provocaban cada vez mayor resistencia en los sectores que dominaban la vida económica del país. Luego de un complot militar que intentó derrocar a Farrel y a Perón, el vicepresidente desautorizó toda gestión en favor de su candidatura y negó sus aspiraciones presidenciales. Sin embargo, no pudo despejar la desconfianza de la oposición política acerca de sus propósitos ni evitar que se intensificara la presión para que el gobierno fijara fecha de elecciones nacionales. Las declaraciones del vicepresidente negando su intención de presentarse como candidato mereció la aprobación del diario de la familia Julio. En su opinión, el gobernante "que tanto ha trabajado para estructurar un nuevo orden en el campo de las relaciones sociales entre el obrero y el capital" actuaba acorde con las necesidades de la hora puesto que, de integrar una fórmula, se estarían reiterando procedimientos propios del régimen que el golpe había depuesto: "Ningún candidato deberá contar en caso alguno con el auspicio oficial y que la prescindencia del gobierno en este aspecto debe ser absoluta, por cuanto es menester terminar con el régimen de las sucesiones facilitadas por la acción oficial" 33 .

A continuación concluía que, tanto los intentos de apadrinar candidatos desde el Estado como las pretensiones de imponer condicionamientos al futuro gobierno implicaban "la proyección de una lamentable sombra en el juicio valorativo de los ideales del movimiento del 4 de junio".

En la medida en que se fueron sucediendo los vaivenes y alternativas de la lucha por el poder en el seno del gobierno militar, el diario fue endureciendo su posición, convirtiendo la exigencia de urgente restitución al pueblo de sus derechos cívicos en el eje estructurador de su discurso:

\footnotetext{
El país espera ahora, haciendo fe a la palabra de sus gobernantes, que no se dilate más tiempo del necesario la culminación de la obra de los hombres de la revolución, cuyo desemboque en la vuelta integral al imperio de las instituciones jurídicas constituye ya una verdadera necesidad para el normal desenvolvimiento de todas las actividades de la Nación. ${ }^{34}$
}

32 "La convocatoria a elecciones generales", La Nueva Provincia, 7 de enero de 1945, p. 2.

33 "Las candidaturas presidenciales y la voluntad del país", La Nueva Provincia, 24 de abril de 1945, p. 2.

34 “En el segundo aniversario de la revolución”, La Nueva Provincia, 4 de junio de 1945, p. 2. 
Tiempo después, cuando se dieron disputas dentro del propio régimen militar entre Perón y oficiales contrarios, el matutino bahiense siguió con mucha atención tales acontecimientos.

Cuando finalmente se conoció la noticia del alejamiento de Perón del gabinete de Farrell, LNP dedicó su página editorial a reflexionar sobre la trascendencia de este hecho para el país:

\begin{abstract}
Se disipa con estos hechos un estado de confusión y de beligerancia espiritual mantenido, en plurales aspectos, por una obstinada pero cada vez más ostensible tendencia de girar la solución de los problemas políticos vinculados con el proceso de normalidad constitucional, en función de determinadas miras personales.

La revolución del 4 de junio no podía desembocar en una suerte de "continuismo" como el que se propugnaba desde la esfera absorbente regida por aquel espíritu. El movimiento de 1943 enastó una bandera sobrepuesta a toda finalidad individual o de núcleo. Había que salvar a la patria del derrumbe a que la precipitaba el desgobierno, y fuera de esa finalidad transcendental, cualquier cosa que se hiciese implica interpolar en el cuadro un oscuro factor de perturbación.

Los acontecimientos de los últimos tiempos no podían ser más intranquilizadores. Conocida la renuncia del vicepresidente de la Nación aquel estado de preocupación ha cedido casi instantáneamente. ${ }^{35}$
\end{abstract}

La transcripción de este extenso párrafo se justifica porque en él reconocemos algunos de los ejes temáticos de la cultura política del diario. En efecto, como ya hemos señalado, $L N P$ rechazaba contundentemente una continuación del gobierno militar, ya que aquél sólo se justificaba como "salvador" de la democracia.

Un día antes de la manifestación popular del 17 de octubre, el matutino bahiense realizaba un balance del periodo transcurrido y planteaba que el alejamiento del coronel Perón aseguraría a los partidos tradicionales el tiempo suficiente para proceder a su reestructuración, al mismo tiempo que permitiría la consolidación de nuevas agrupaciones políticas:

\footnotetext{
¿Marcha ya el país definitivamente al encuentro de su verdadero rumbo? Los últimos acontecimientos autorizan la respuesta afirmativa.

[...]

Siempre será vano el esfuerzo de los hombres que, erigidos por sí mismos en salvadores de la patria, pretenden detener, con murallas de barro, la corriente fluvial que riega y fecunda la tierra espiritual argentina desde el alba de su nacimiento.

Ni demagogia, ni libertad. El derecho constitucional, con sus correlativas obligaciones, como única guía para todos. ${ }^{36}$
}

\title{
El 17 de octubre de 1945, miles de trabajadores provenientes del cordón
}

35 “La renuncia del vicepresidente de la Nación, Cnel. Juan D. Perón”, La Nueva Provincia, 10 de octubre de 1945 , p. 2.

36 “La enseñanza de los sucesos que ha vivido el país”, La Nueva Provincia, 16 de octubre de 1945, p. 2. 
industrial del Gran Buenos Aires ocuparon la Plaza de Mayo, decididos a no moverse hasta que Perón apareciera en los balcones de la Casa Rosada. Por la noche, finalmente el coronel pudo estrenar su saludo con los brazos en alto. Perón se había impuesto y ya ocupaba un lugar destacado en la política nacional.

Respecto de esos sucesos, el diario de la familia Julio no emitió ningún comentario referencial sino que sólo dedicó parte una de sus páginas a narrar lo ocurrido a manera de crónica ${ }^{37}$. Frente a ello resulta oportuno tener en cuenta el planteo de Borrat ${ }^{38}$, quien enuncia la importancia que tienen los comentarios en la conformación de un periódico, otorgando a los acontecimientos un rango más elevado que el de aquellos temas que solamente son narrados. El autor dice que pasar del relato al comentario es entrar en el campo de la opinión, que se articula con la interpretación explícita, y con ello pasa a ser interpretación explícita con evaluación. De esta manera, al excluir de sus comentarios lo sucedido, vemos claramente la postura adoptada por el diario y la intención de no dar importancia al suceso, disminuyendo seguramente la repercusión entre sus lectores. De esta manera, y siguiendo a Verón, el periódico se dirige al prodestinatario, es decir, el destinatario positivo, el partidario, aquel que se corresponde con el receptor que participa, se adhiere y persigue las mismas ideas, valores y objetivos del enunciador político. Por lo tanto, el discurso político sirve a los efectos de reforzar el lazo con éste. ${ }^{39}$

Pocos días después, ocurrió un hecho significativo para la historia de este movimiento: la creación del Partido Laborista, por parte de los sindicatos afines al coronel para lanzar su candidatura. Esta misma no fue bien recibida por el matutino local, y frente a ello reiteró con renovado énfasis su llamado a la reestructuración interna de las fuerzas tradicionales a las que consideraba legítimamente representativas de la voluntad popular, identificando claramente al "enemigo" político en la persona del coronel.

A partir de ello, el diario comenzó a publicar distintas editoriales mostrando su disconformidad con la aspiración del militar:

Proclamada recientemente cierta candidatura presidencial desde una esfera extraña a la del ambiente que debe rodear los actos de ese carácter, sus adláteres en el llano no pueden seguir peor camino que el emprendido. Si, como se ha sostenido, aquella candidatura cuenta con el respaldo de no sabemos qué fuerzas o exponentes auténticos del trabajo, ¿̇para qué la apelación a medios de lucha como los que se ha empezado a ensayar? 40

37 "Fue puesto en libertad el coronel Perón, mediante una huelga parcial, que culminó en una concentración en la Plaza de Mayo", La Nueva Provincia, 18 de octubre de 1945, p. 4.

38 Héctor Borrat, ., p. 138.

39 Eliseo Verón, Emilio de Ipola, Noemí Goldman y Oscar Landi, El discurso político. Lenguaje y acontecimientos, p. 89.

40 “Una maniobra política que no puede prosperar en el país", La Nueva Provincia, 30 de octubre de 1945, p. 2. 
Dicha oposición no sólo hace referencia a la persona del coronel; lo que más preocupa al diario es la ayuda recibida desde el propio estado para su campaña que comienza:

\footnotetext{
Se denuncia, cada vez más firmemente y por conducto de órganos autorizados de la conciencia política y gremial, que determinados resortes oficiales vienen actuando por momentos con mayor impudicia a favor de la candidatura proclamada hace semanas y que, con recursos del Estado, se están organizando también nuevas "marchas" y "concentraciones", las que, a título de una supuesta ratificación de la llamada política social cumplida en los dos últimos años, tenderían a crear nuevos actos de violencia e intimidación pública. ${ }^{41}$
}

A pesar de que $L N P$ vio con agrado la intervención del Estado en materia social, creyendo que con ella se buscaba modernizar las relaciones entre trabajo y capital, y pese a haber expresado su coincidencia con los objetivos declarados por las autoridades (en el sentido de propender a un estado de mayor bienestar social del pueblo), luego de lanzada la candidatura de Perón, veía a dicha política social inaugurada por éste como una política de neto corte fascista, que tenía como mera finalidad atraerse el apoyo del electorado: “... las masas -las masas en su representación ciudadana y no en su concepción unilateral de gremios dirigidos con el mismo criterio con que Mussolini respaldó el sindicalismo sui géneris de su concepción antilibertaria- no pueden llamarse a engaño" ${ }^{42}$.

A partir de aquí, el matutino comenzará a hacer constante hincapié en lo que consideraba "elementos fascistas" del candidato surgido de las filas del gobierno militar. Sólo se hacía mención al candidato en estos términos y por otro lado recurrió a la indiferencia frente a la campaña del partido laborista y frente a los actos en el contexto de la misma, excepto para resaltar hechos de violencia o sospechas de ayuda económica por parte del estado.

Desde ese lugar, trazó la configuración de la "arena política" y, siguiendo su cultura política, se opuso a un "personalismo perturbador", argumentando que los partidos que surgían exclusivamente para la lucha eleccionaria no tenían esperanza de prosperar en el tiempo: "Un partido no puede improvisarse. Para que responda realmente a una calidad es necesario algo más que una circunstancia gubernativa propicia o el espejismo de condiciones populares supuestamente favorables. Un partido nace en el pueblo, viene del pueblo y se realiza con el pueblo"43.

En este sentido, el matutino se expresa con la plena convicción de interpretar la voluntad de la ciudadanía y continuamente apuesta a la in41 "Las promesas oficiales y lo que espera ahora el país", La Nueva Provincia, 2 de noviembre de 1945, p. 2. 42 "Los próximos comicios", La Nueva Provincia, 30 de noviembre de 1945, p. 2.

43 "Partidos improvisados y partidos democráticos", La Nueva Provincia, 15 de enero de 1946, p. 2. 
teligencia del pueblo en la confianza de que éste rechazaría la propuesta de Perón por considerarla demagógica.

Ya expresamos cómo el diario, como todo actor del sistema político, combinó silencios estratégicos con mensajes de apoyo, demandas y denuncias ${ }^{44}$. Los sucesos que se fueron dando entre octubre de 1945 y febrero de 1946 no escaparon a dicha regla, ya que el matutino sostuvo en este periodo a la fórmula de la Unión Democrática, al tiempo que negaba que la coalición laborista contase con apoyo popular.

Por otro lado, el matutino de la familia Julio insistía en señalar la extrema polarización del campo político y entendía que el momento histórico era sumamente importante para definir un modelo de país. Para ello recurría a un pasado fundacional ("los valores tradicionales de la patria, representados en la figura del general San Martín están comprometidos por la aparición de figuras foráneas”) ${ }^{45}$, siguiendo aquel concepto de la cultura política, donde dejábamos en claro que las raíces filosóficas y las referencias históricas juegan también un rol importante como fundamentos de las culturas políticas, porque no existe cultura política coherente que no comprenda, precisamente, una representación de la sociedad ideal y los medios de llegar a tenerla.

Llegada la hora de los comicios, el periódico una vez más dejaba expresado su apoyo a la Unión Democrática y en esta ocasión lo hacía dedicando la totalidad de una página para promover la candidatura Tamborini-Mosca, además de considerar nuevamente al partido laborista como una expresión del fascismo europeo:

\footnotetext{
Ciudadano: La de mañana no es una elección común, porque en ella lucha la democracia contra el totalitarismo. La pacificación del país y el afianzamiento de la armonía entre los pueblos de América dependen del resultado de esta histórica elección. No olvide Ud. que el radicalismo lucha por la justicia social sin el precio de la libertad individual. No olvide tampoco que nuestro pueblo democrático soporta ahora el mismo sistema de violencia y engaño nazifascista que llevaron a Italia y a Alemania a su propio aniquilamiento. ${ }^{4}$
}

Superadas las elecciones (luego de haber dedicado varias de sus columnas editoriales a elogiar la corrección con que los comicios se habían desarrollado), frente a los resultados que iba arrojando el escrutinio, el diario comenzó a moderar su discurso y con la asunción del nuevo gobierno demandaba la adecuación del mismo a la Constitución, además de preocuparse porque el gobierno representara a toda la Argentina y no sólo a

44 Héctor Borrat, op. cit., p. 139.

45 "La ciudadanía debe meditar profundamente los deberes políticos de la hora actual”, La Nueva Provincia, 12 de febrero de 1946, p. 2.

46 “Unión Cívica Radical. Tamborini-Mosca”, La Nueva Provincia, 23 de febrero 1946, p. 3. 
un sector de la población ${ }^{47}$. Nuevamente reconocemos en ello uno de los ejes temáticos de su cultura política.

\section{Reflexiones finales}

En los últimos años la noción de cultura política ocupa un lugar importante en la reflexión de las ciencias sociales. Definida a la vez como una suerte de código y un conjunto de referentes (creencias, valores, memoria específica, vocabulario propio) formalizados en el seno de un partido, familia o tradición política, la misma constituye una aproximación fecunda para el estudio de las representaciones colectivas y los imaginarios sociales en la medida en que permite establecer conexiones entre lo político y lo socio-cultural ${ }^{48}$.

Siguiendo la definición anterior, una cultura política constituye un conjunto coherente de diversos componentes, reunidos en un todo homogéneo que permite caracterizar la identidad de un agente social dado, sea éste individual o colectivo, y que conduce a proveerlo de una determinada visión del mundo. En dicha visión confluyen básicamente una determinada matriz filosófica, una lectura común y normativa del pasado histórico y una noción institucional que se traduce en una determinada concepción de la organización política del estado, elementos que constituyen un universo significativo que se expresa a través de un vocabulario conformado por palabras claves y fórmulas repetitivas.

Con respecto a los vectores de difusión de una cultura política, la prensa escrita constituyó, fundamentalmente en el periodo aquí abordado, uno de los principales "agentes socializadores" para los lectores que frecuentaban las páginas editoriales de los periódicos de la época ${ }^{49}$. De allí la importancia de abordar su análisis a partir de la perspectiva de la cultura política que vehiculizaban desde ese espacio de sus superficies redaccionales y, por consiguiente, nuestra decisión de escoger esta aproximación a $L N P$ en tanto objeto de estudio.

Nuestro intento de abordar el estudio de la cultura política de $L N P$ nos permite realizar unas primeras consideraciones sobre la misma. Durante el periodo 1943-1946 vemos que el diario vehiculizó una cultura política hecha de referencias al pasado, de una concepción del futuro político del país y de fidelidad a la Constitución, cuyo conjunto constituye un todo coherente y armonioso. Sin duda sus lectores se reconocieron

47 "La política constructiva que espera el país del nuevo gobierno", La Nueva Provincia, 4 de junio de 1946, p. 3. 48 Laura Llull, "Reflexiones en torno a la cultura política de un diario bahiense: La Nueva Provincia durante las presidencias radicales (1916-1930), en Mabel Cernadas y Patricia Orbe (comps.), Itinerarios de la prensa. Cultura política y representaciones en Bahía Blanca durante el Siglo XX, pp. 155-164.

49 Laura Llull, Prensa y Política en Bahía Blanca..., op. cit., p. 461. 
en estas representaciones y comulgaron, en mayor o menor medida, con este discurso específico que constituyó un elemento de comunión para quienes se identificaban con esta particular visión de lo político.

Durante el periodo estudiado, la exitosa trayectoria como empresa periodística del matutino fundado por Enrique Julio le permitió ocupar una posición relevante en la organización del campo periodístico bahiense. Además del prestigio que le otorgaba ser el único diario fundado en el siglo anterior que aún se publicaba en la ciudad, podía exhibir su éxito en los ámbitos profesional y comercial, condiciones que le conferían un capital simbólico que ningún otro agente del campo poseía. Dicho capital seguramente influyó para que sus reflexiones editoriales sobre temas políticos fuesen no sólo leídas con atención por sus lectores, sino también tenidas en cuenta por los otros periódicos que por entonces se publicaban en Bahía Blanca.

El discurso político que puso en escena en sus reflexiones editoriales reiteró y profundizó argumentos que $L N P$ ya había adelantado en ocasión de producirse el golpe de 1943. En tanto medio de comunicación, $L N P$ buscó informar detalladamente a sus lectores sobre los sucesos que llevaron paulatinamente al coronel Perón a la escena política nacional. El matutino bahiense expuso su discurso político no sólo en sus reflexiones editoriales sino también en las noticias, al alternar "presencias y ausencias" de las mismas.

El diario de la familia Julio abordó este tema que se convirtió en el eje organizador del debate público de la época. Desde sus editoriales interpeló a los lectores bahienses y de la zona proponiendo distintas interpretaciones de la función que le correspondía a los partidos políticos y sus dirigencias en la etapa que se iniciaba con la llegada de los militares al gobierno. Es decir que las características del nuevo escenario político preocuparon al matutino, quien reflexionó preferentemente sobre la eficacia y legitimidad del sistema de partidos como medio de asignación del poder político, lo cual nos permite considerar sus puntos de vista como posición en el campo a partir de la cual se instituye su visión particular de lo político.

En el sistema de referencias históricas de la cultura política vehiculizada por $L N P$ tenían una centralidad especial los ideales de mayo y con él la fundación de una nación democrática.

Los editoriales fueron entonces espacios donde $L N P$ puso en escena las diversas representaciones que conformaban su cultura política. Esta última, tal como se manifiesta durante el periodo correspondiente al "gobierno de los coroneles", constituyó un marco de referencia, con una lógica y un principio de coherencia propios, a través del cual el diario 
pensó las realidades políticas de aquellos años.

Dicha cultura política estuvo atravesada por la reflexión sobre la necesidad de retomar la senda de una verdadera democracia, donde las FF.AA jugaban un rol de "moralizadoras" de la sociedad para luego dar lugar a los partidos orgánicos. Esos partidos orgánicos tenían, para $L N P$, una misión pedagógica en una democracia que se pensaba en camino de progresivo perfeccionamiento.

Dos componentes caracterizaron la cultura política del matutino: el sentido del progreso democrático y el marcado optimismo con que leyó la coyuntura de la época. $L N P$ celebraba la imagen del país en marcha progresiva hacia la perfección democrática. No obstante ello, esto último comenzó a cambiar cuando se conoció la candidatura del coronel Perón. Por todo lo dicho, el apoyo inicial al gobierno surgido en junio de 1943 derivó, en un principio, de que el movimiento había puesto fin a una etapa marcada por el fraude.

La "enemistad anunciada" la encontramos a lo largo de sus editoriales, donde el diario reconoce sólo a los partidos orgánicos con una trayectoria en la política como verdaderos elementos de la democracia. Frente a ello, a medida que se va perfilando la candidatura de Perón, la crítica va a ser lógica según la cultura política socializada por el diario.

A pesar de que el diario vio con agrado, e incluso con entusiasmo, la labor social implementada a partir de la llegada del coronel Juan Domingo Perón a la Secretaría de Trabajo y Previsión, no mantuvo la misma postura frente al surgimiento de éste como candidato a presidente. Además de no compartir la idea de una candidatura apoyada desde el Estado y de considerar a aquella como una práctica continuista del régimen conservador, pensó a la misma como una extensión del nazi-fascismo en la Argentina. Por otro lado, en el imaginario político del matutino, al acercarse las elecciones de febrero de 1946, el radicalismo ocupaba el principal lugar porque lo consideraba una entidad eminentemente democrática.

Puede concluirse, entonces, que $L N P$ se convirtió en un vector principal de difusión de las culturas políticas durante el siglo XX, ya que el mismo, como actor político, contribuyó a definir la identidad política de sus lectores, inspirando sentimientos, moldeando sus sensibilidades y difundiendo sus representaciones. Por ello consideramos que el análisis de la prensa escrita local y regional constituye un área de estudios en la que los investigadores pueden realizar inestimables aportes para la historia política y, en particular, para la historia de las representaciones sociales. 


\section{Fuentes primarias}

Democracia; una voz bahiense para toda la provincia. Bahía Blanca, años 1943 a 1946.

El Régimen; bisemanario antiradical "Órgano del partido conservador”, Bahía Blanca, años 1943 a 1946.

La Nueva Provincia, Bahía Blanca, años 1943 a 1946.

Nuevos Tiempos, Bahía Blanca, años 1943 a 1946.

\section{Bibliografía}

AA.VV. La Construcción de la Nación Argentina. El rol de las Fuerzas Armadas. Debates Históricos en el marco del Bicentenario 18102010. Ministerio de Defensa, Buenos Aires, 2010.

ALTAMIRANO, Carlos. Bajo el signo de las masas (1943-1973). Ariel, Buenos Aires, 2001.

AMABLE, Hugo. Discursos políticos en escena. Editorial Universitaria, Misiones, s/a.

BOBBIO, Norberto, Nicola Matteucci y Gianfranco Pasquino. Diccionario de Política. Siglo XXI, México, 2005.

BORRAT, Héctor. El periódico, actor político. Gustavo Gilli, Barcelona, 1989.

. "El periódico, actor del sistema político", en Revista Analisi: Quaderns de Comunicació i Cultura, 1989, pp. 67-80. Disponible en: www.raco.cat/index.php/Analisi/article/download/41078/89080. Accedido el 20 de marzo de 2013.

BUCHRUCKER, Cristian. Nacionalismo y Peronismo. La Argentina en la crisis ideológica mundial. 1927-1955. Sudamericana, Buenos Aires, 1987.

CERNADAS de Bulnes, Mabel. "Cuando los socialistas gobernaron Bahía Blanca: la intendencia de Agustín de Arrieta (1932-1935) y el desafío de transformar la cultura política 〈criolla〉", en Estudios Sociales. Revista universitaria semestral, año XXIII, núm. 44, Universidad Nacional del Litoral, Santa Fe, Argentina, primer semestre 2013, pp. 101-122.

CERNADAS de Bulnes, Mabel y Laura Llull. "Del apoyo a la crítica: itinerario de las ideas de La Nueva Provincia en los orígenes del peronismo", Separata del Undécimo Congreso Nacional y regional de Historia Argentina, Academia Nacional de la Historia, Buenos Aires, 
2001.

CERNADAS DE BULNES, Mabel y Roberto Bustos Cara (eds.). La cultura en cuestión. Estudios interdisciplinarios del Sudoeste Bonaerense. Universidad Nacional del Sur, Buenos Aires, 2004.

CERNADAS, Mabel y Patricia Orbe (comps.). Itinerarios de la prensa. Cultura política y representaciones en Bahía Blanca durante el Siglo XX. Bahía Blanca, EdiUNS, 2013.

DA ORDEN, María Liliana y Julio César Melon Pirro. Prensa y peronismo. Discursos, prácticas, empresas, 1943-1958. Prohistoria, Rosario, 2007.

DE JORGE, Carlos. "La visión del peronismo en el interior del país a través de los diarios capitalinos", Red de Estudios sobre el Peronismo. Disponible en http://redesperonismo.com.ar/archivos/CD2/DeJorge.pdf. Accedido el 27 de junio de 2012.

DE PRIVITELLIO, Luciano. "La política bajo el signo de las masas", en Alejandro Cattaruzza, Nueva historia argentina. Tomo VII, Editorial Sudamericana, Buenos Aires, 2001.

EBERLE, Adriana y Laura Llull. "Las fuerzas políticas y sociales bahienses ante el pronunciamiento militar de 1943", en Cuartas Jornadas de Historia Regional Bonaerense, Bahía Blanca, 1987.

GALVÁN MORENO, Carlos. El periodismo argentino. Editorial Claridad, Buenos Aires, 1944.

GAMBINI, Hugo. Historia del peronismo. El Poder Total (1943-1951). Planeta, Buenos Aires, 1999.

GOLDMAN, Noemí. El discurso como objeto de la historia. Hachette, Buenos Aires, 1989.

GONZÁLEZ REYNA, Susana. "El periódico como actor político que media entre los acontecimientos de la realidad social y el público lector". Ponencia en el Congreso Internacional Derechos Humanos y Comunicación, México, 2009. Disponible en http://www.iamcr.org/ component/docman/doc_download/286-2009-mco-gonzalez-reyna. Accedido el 21 de marzo de 2013.

HOROWICZ, Alejandro. Los cuatro peronismos. Hyspamérica, Buenos Aires, 1986.

LANDI, Óscar. Reconstrucciones. Las nuevas formas de la cultura política. Puntosur, Buenos Aires, 1988.

LEONI, María Silvia y María del Mar Solís Carnicer (comps.). La política en los espacios subnacionales. Provincias y territorios en el nordeste argentino (1880-1955). Prohistoria Ediciones, Rosario, Colección Universidad, 19, 2012.

LLUL, Laura. Prensa y política en Bahía Blanca. La Nueva Provincia en 
las presidencias radicales, 1916-1930. Bahía Blanca, Ediuns, 2005. . "Aproximación a las ideas políticas de un periódico bahiense. La Nueva Provincia y la legislación Sáenz Peña”, en Cuadernos del Sur. Historia, núm. 27, EdiUns, Bahía Blanca, 1998, pp. 109-130. . "El diario La Nueva Provincia y el golpe de estado de 1966", en Cuadernos del Sur. Historia. Núm. 33, EdiUns, Bahía Blanca, 2003. . "El periódico como vector de internalización de una cultura política: La Nueva Provincia (1916-1922)”, en Roberto Bustos Cara y Mabel N. Cernadas de Bulnes (eds.), Estudios Regionales Interdisciplinarios II. EDIUNS, Bahía Blanca, 2000.

. "La política bonaerense mirada desde Bahía Blanca. La Nueva Provincia ante la respuesta conservadora al desafío de la democratización, 1912-191”, en Estudios Sociales. Revista Universitaria Semestral, año XIII, núm. 24, Universidad Nacional del Litoral, Santa Fe, Argentina, primer semestre 2003, pp. 9-29.

. "La prensa escrita como agente socializador de culturas políticas. Estudio de caso: el diario La Nueva Provincia de Bahía Blanca (1916-1930)", en e-Latina, Revista electrónica de estudios latinoamericanos. Volumen 2, núm. 5, Facultad de Ciencias Sociales, Universidad de Buenos Aires, octubre-diciembre de 2003. Disponible en http://www.catedras.fsoc.uba.ar/udishal/elatina/o5oct-dic2003. pdf. Accedido el o4 de mayo de 2013.

LÓPEZ, Ernesto. El primer Perón. El militar antes que el político. Capital Intelectual, Buenos Aires, 2009.

LUNA, Félix. El 45. Crónica de un año decisivo. Sudamericana, Buenos Aires, 1990.

MACHINNON, María Moira. "Sobre los orígenes del peronismo. Notas introductorias", en Waldo Ansaldi (ed.), Representaciones inconclusas: las clases, los actores y los discursos de la memoria, 1912-1946. Biblos, Buenos Aires, 1995, pp. 223-253.

MACOR, Darío y César Tcach. La invención del peronismo en el interior del país. Universidad Nacional del Litoral, Santa Fe, 2003.

MARCILESE, José. El primer peronismo en Bahía Blanca. De la génesis a la hegemonía (1943-1955). Tesis doctoral inédita, Universidad Nacional del Sur, Bahía Blanca, 2008.

NEIBURG, Federico. Los intelectuales y la invención del peronismo. Alianza Editorial, Buenos Aires, 1998.

PALERMO, Vicente. El siglo peronista. Punto de Vista, núm. 89, Buenos Aires, 2007.

PLOTKIN, Mariano. Mañana es San Perón. Ariel, Buenos Aires, 1993.

RAPOPORT, Mario. Historia económica, política y social de la Argenti- 
na (1880-2000). Ediciones Macchi, Buenos Aires, 2000.

RODRÍGUEZ, Miguel Angel. "Las rutas de la Cultura Política”, en Metapolítica. Vol. 1, núm. 2, 1997, pp. 283-289.

RODRÍGUEZ GONZÁLEZ, Félix. Prensa y lenguaje político. Madrid, Instituto de Cultura Juan Gil Albert, 1991.

ROMERO, José Luis. Breve historia de la Argentina. Tierra Firme, Buenos Aires, 2003.

. Las ideas políticas en Argentina. Fondo de Cultura Económica, Buenos Aires, 2001.

SAÍTTA, Sylvia. Regueros de tinta. El diario Crítica en la década de 1920. Sudamericana, Buenos Aires, 1998.

SEBRELI, Juan José. Los deseos imaginarios del peronismo. Legasa, Buenos Aires, 1983.

SIDICARO, Ricardo. La política mirada desde arriba: las ideas del diario La Nación. 1909-1989. Sudamericana, Buenos Aires, 1995.

SIRVÉN, Pablo. Perón y los medios de comunicación (1943-1955). Centro Editor de América Latina, Buenos Aires, 1984

TORRE, Juan Carlos. La vieja guardia sindical y Perón. Sobre los orígenes del peronismo. Sudamericana, Buenos Aires, 1990.

TORRE, Juan Carlos. Nueva historia Argentina. Los años peronistas (1943-1955). Tomo VIII, Sudamericana, Buenos Aires, 2002.

ULANOVSKY, Carlos. Paren las rotativas. Historia de los grandes diarios, revistas y periodistas argentinos. Espasa, Buenos Aires, 1997.

VAN DIJK, Teun A. La noticia como discurso. Comprensión, estructura y producción de la información. Paidós, Barcelona, 1990.

. Estructuras y funciones del discurso. Siglo XXI, México, 1980.

VERÓN, Eliseo, Emilio de Ipola, Noemí Goldman, y Óscar Landi. El discurso político. Lenguaje y acontecimientos. Hachette, Buenos Aires, 1987.

WALDMAN, Peter. El peronismo. Sudamericana, Buenos Aires, 1983.

WEINBERG, Félix. Historia del sudoeste Bonaerense. Plus Ultra, Buenos Aires, 1988.

WEINBERG, Félix. Manual de historia de Bahía Blanca. Departamento de Ciencias Sociales de la Universidad Nacional del Sur, Buenos Aires, 1978.

ZANATTA, Loris. Del Estado liberal a la nación católica. Iglesia y ejército en los orígenes del peronismo 1930-1943. Universidad Nacional de Quilmes, 1996. 